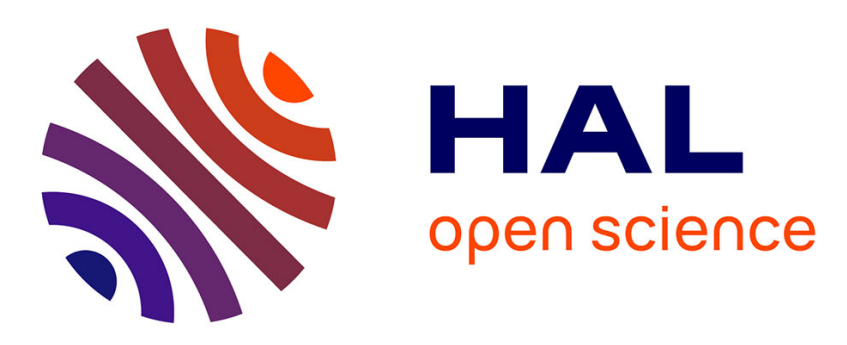

\title{
Fertility preservation strategies for rectal cancer in reproductive-age women
}

\author{
Samuel Khiat, Pauline Bottin, Jacqueline Saias-Magnan, Mohamed Gasmi, \\ Pierre Orsoni, Blandine Courbiere
}

\section{- To cite this version:}

Samuel Khiat, Pauline Bottin, Jacqueline Saias-Magnan, Mohamed Gasmi, Pierre Orsoni, et al.. Fertility preservation strategies for rectal cancer in reproductive-age women. Future Oncology, 2019, 15 (22), pp.2635-2643. 10.2217/fon-2019-0083 . hal-02293178

\section{HAL Id: hal-02293178 https://hal.science/hal-02293178}

Submitted on 20 Sep 2019

HAL is a multi-disciplinary open access archive for the deposit and dissemination of scientific research documents, whether they are published or not. The documents may come from teaching and research institutions in France or abroad, or from public or private research centers.
L'archive ouverte pluridisciplinaire HAL, est destinée au dépôt et à la diffusion de documents scientifiques de niveau recherche, publiés ou non, émanant des établissements d'enseignement et de recherche français ou étrangers, des laboratoires publics ou privés. 


\title{
Fertility preservation strategies for rectal cancer in age-reproductive women
}

\author{
Samuel Khiat ${ }^{1}$, Pauline Bottin ${ }^{1}$, Jacqueline Saïas-Magnan ${ }^{1}$, Mohamed Gasmi², Pierre \\ Orsoni $^{3}$, Blandine Courbiere*,1,4 \& GRECOT (Groupe de Recherche et d'Etude en \\ Cryoconservation Ovarienne et Testiculaire) \\ ${ }^{1}$ Pôle Femmes-Parents-Enfants - Centre Clinico-Biologique d'AMP-CECOS, Plateforme Cancer et Fertilité ONCOPACA-Corse, \\ AP-HM La Conception, 147 bd Baille, 13005 Marseille, France \\ ${ }^{2}$ Department of Gastroenterology, AP-HM, Aix Marseille Univ, Hôpital Nord, Marseille, France \\ ${ }^{3}$ Department of Digestive Surgery, AP-HM / Aix Marseille Univ, Hôpital Nord, Marseille, France \\ ${ }^{4}$ Aix Marseille Univ, Avignon Université, CNRS, IRD, IMBE, 13397, Marseille, France \\ *Author for correspondence: Tel.: +00 334913829 00; blandine.courbiere@univ-amu.fr
}

Despite rectal cancer is unusual before 40 , fertility preservation (FP) remains a major concern for these age-reproductive women. Treatment usually involves pelvic radiotherapy, neoadjuvant chemotherapy, and surgery of rectum and mesorectum resection, at high risk of impairing fertility in women with risks of premature ovarian failure and radio-induced uterus damage. To date, there is no consensus on FP strategy for rectal cancer. We shared experiences between oncofertility experts from a French research network GRECOT about a case of rectal cancer in a young woman. Indications, advantages and disadvantages of different FP strategies were discussed: ovarian transposition, cryopreservation of ovarian cortex and oocyte vitrification. This case was the starting point that led to develop a French multidisciplinary e-meeting for sharing experiences and for suggesting the best strategy when faced with a complex oncofertility case.

Keywords: fertility preservation $\bullet$ oocyte vitrification $\bullet$ ovarian tissue cryopreservation $\bullet$ ovarian transposition $\bullet$ rectal cancer

Rectal cancer is a relatively rare disease, with an incidence of less than $1 \%$ in USA. In France, about 220 women under 40 are concerned per year. However, US epidemiological data have shown an increase of rectal cancer cases in women under 40 [1]. Management of rectal cancer most often combines neoadjuvant chemoradiotherapy and surgical treatment including total proctectomy with total mesorectum excision [2]. Usually, pelvic radiotherapy delivers doses of at least $45 \mathrm{~Gy}$, which are strongly reprotoxic for both the ovarian reserve and the uterus [3]. In addition to the risk of dose-dependent premature ovarian failure (POF), radiotherapy induce inflammation and myometrial fibrosis [4]. Fertility preservation (FP) before cancer treatment has been the subject of international guidelines and must be integrated into the personalized care pathway of all children and age-reproductive women [5]. However, there is no consensus on FP strategies for rectal adenocarcinoma. The possible FP techniques are transposing ovaries out of the irradiation field, oocyte vitrification and ovarian tissue cryopreservation. However, these techniques do not prevent the consequences of uterine irradiation. Based on a clinical observation, we reported the 'no consensus status' of the FP strategy to offer to age-reproductive women with rectal cancer before starting treatment. In France, a case study of rectal cancer in a young age-reproductive woman was discussed between oncofertility experts from a research network GRECOT, that pointed out the difficulties to choose the best FP strategy for this pathology. The objective of our article was to discuss specific FP strategies for rectal cancer and showed how a clinical case could induce a new health-network think thank with the set-up of a national e-meeting dedicated to oncofertility complex cases.

\section{Special report}

Our oncofertility team was faced with the case of a 26-year-old woman, treated for Crohn's disease and diagnosed with a lower rectum adenocarcinoma. The tumor was classified T3 N0 M0 by pelvic MRI and pelvic-abdominalthoracic CT. Oncologists recommended for this lower rectum tumor a combined chemoradiotherapy with a total 


\begin{tabular}{|c|c|}
\hline Expert $n^{\circ} 1$ & $\begin{array}{l}\text { COS for oocyte vitrification followed by ovariectomy } 15 \text { days later for OCP } \\
\text { No SOT }\end{array}$ \\
\hline Expert $n^{\circ} 2$ & $\begin{array}{l}\text { COS for oocyte vitrification followed by ovariectomy } 15 \text { days later for OCP } \\
\text { No SOT }\end{array}$ \\
\hline Expert $n^{\circ} 3$ & SOT and OCP \\
\hline Expert $n^{\circ} 4$ & $\begin{array}{l}\text { COS for oocyte vitrification followed by ovariectomy } 15 \text { days later for OCP } \\
\text { No SOT } \\
\text { Uterine transposition }\end{array}$ \\
\hline Expert $n^{\circ} 5$ & $\begin{array}{l}\text { Difficuly to perfom SOT with stimulated and punctured ovaries } \\
\text { Bilateral SOT } \\
\text { In second line, after anticancerous treatment: COS for oocyte vitrification } \\
\text { Uterus: prone position during radiotherapy }\end{array}$ \\
\hline Expert $n^{\circ} 6$ & Uterine transposition \\
\hline Expert $n^{\circ} 7$ & $\begin{array}{l}\text { Bilateral SOT (Despite SOT, left ovary is less protected against ionizing radiation) } \\
\text { Advise to associate partial left ovariectomy for OCP during the same surgical time. }\end{array}$ \\
\hline Expert $n^{\circ} 8$ & Bilateral partial ovariectomy $(1 / 3)$ for OCP and bilateral SOT during the same surgical time \\
\hline Expert $n^{\circ} 9$ & Left ovariectomy for OCP and right SOT \\
\hline
\end{tabular}

dose of 50.4 Gy and capecitabin at dose of $800 \mathrm{mg} / \mathrm{m}^{2}$ twice daily before surgery. The patient was referred to the ONCOPACA-Corse Cancer and Fertility network to discuss options of FP before treatment. Ovarian reserve assessment showed a antral follicle count with 15 follicles per ovary and anti-Müllerian hormone (AMH) serum level before treatment was $1.96 \mathrm{ng} / \mathrm{ml}$. Because of different opinions in our unit between physicians concerning 'best' technique to be proposed, and at the patient's request, a national multidisciplinary consultation was sent by mail to expert members of the GRECOT (Groupe de Recherche en Cryoconservation Ovarienne et Testiculaire) after anonymization of the identifying data. Results of this multiexpert consultation is reported in Table 1. Because of foreseeable technical difficulties to perform ovarian surgery on stimulated and punctured ovaries, all opinions rejected ovarian transposition after an oocyte vitrification cycle. Indeed, after stimulation, size of the ovaries is hugely increased and their mobilization from the pelvis could be technically difficult with an increased surgical risk. Suturing distended and punctionned-stimulated ovaries to the anterior abdominal wall is also more difficult. Because of ovarian stimulation and oocyte retrieval consequences on the macroscopic quality of ovarian cortex, embryologists were opposed to perform ovarian cortex cryopreservation (OCP) immediately after ovarian stimulation. After having exposed the different FP strategies with their own advantages and benefits, our patient chose to undergo only a bilateral ovarian transposition. On the other hand, prone position for radiotherapy was recommended by an expert to limit the dose received by the uterus. Before starting any anticancerous treatment, we performed a bilateral ovarian transposition by laparoscopy. Thereafter, an intensity-modulated radiation therapy of 45 Gy was administered in 25 fractions of $1.8 \mathrm{~Gy}$ on the mesorectum with a boost of $5.4 \mathrm{~Gy}$ in three fractions of $1.8 \mathrm{~Gy}$ on the tumor. The mean dose of irradiation received by the uterus was $25.8 \mathrm{~Gy}$. Mean dose received by ovaries was $1.27 \mathrm{~Gy}$. About 6 weeks after the end of radiochemotherapy, a total coloproctectomy with abdominoperineal amputation and definitive ileostomy was performed. Final histopathological analysis diagnosed a $3 \mathrm{~cm}$ ypT2 N0-R0 adenocarcinoma. About 3 months later, a chest CT showed two pulmonary micronodules treated with excision and radiofrequency that corresponded to metastases of rectal adenocarcinoma. Adjuvant chemotherapy with 5-Fluorouracil - folinic acid and oxaliplatin were then administered every 15 days for 6 months.

After 2 years of remission, the patient expressed a desire for pregnancy that was allowed by the oncology team. She had regular cycles, with normal menses. The thickness of the peri-implantation endometrium was measured at $8 \mathrm{~mm}$. As the ovaries were transposed, a reliable antral follicle count could not be performed. The AMH level remained stable at $2.4 \mathrm{ng} / \mathrm{ml}$. At the beginning of a cycle, follicle stimulating hormone was at $6.0 \mathrm{UI} / \mathrm{l}$ and E2 was $32.6 \mathrm{pg} / \mathrm{ml}$. A pelvic MRI was performed in post-treatment to look for postradial uterus damage, and was compared with the MRI performed in pretreatment. No significant changes were observed in uterus measurements, endometrial or myometrial thickness or appearance of the endometrial-myometrial junctional zone (uterus length : $9 \mathrm{~cm}$, antero-posterior diameter: $4 \mathrm{~cm}$; transversal diameter: $5.3 \mathrm{~cm}$ ). The patient and her partner wished to try to achieve a spontaneous pregnancy and did not want to be actively managed with assisted reproduction techniques. About 4 months later, she had a miscarriage at 7 weeks of gestation after a spontaneous pregnancy. 
The patient provided consent to share her medical file and to publish this report.

\section{Discussion}

For patients under 40 , the incidence rate of rectal cancer has increased in the past decades but is still low at $0.5-2$ cases/100,000 per year [1]. Recent data of the InCA (Institute National du Cancer - French National Institute for Cancer) found that rectal cancer before 40 concerns about 220 age reproductive French women per year. Although we have not precise data about the number of women who benefit of a FP for rectal cancer, experience reported by experts was less than five cases per center (unpublished data). Rectal cancer treatments can impair fertility and this case illustrates the difficulty to offer the optimal technique of FP for rare cancers in age-reproductive women. In rectal cancer, radiotherapy is the main threatening treatment for woman's fertility. An estimated threshold dose of $15 \mathrm{~Gy}$ induce ovarian dysfunction between 20 and 30 years [6]. Chemotherapy as capecitabine is not a gonadotoxic chemotherapy and did not add ovarian damage $[7,8]$. Colorectal surgery provides postoperative pelvic adhesions. In a meta-analysis, Broek et al. observed a significantly lower pregnancy rate after colorectal surgery in patients with inflammatory bowel disease than patients with medical treatments only [9]. At our knowledge, the larger retrospective cohort of FP for rectal cancer has been published by Elizur et al. with only six women with rectal cancer [10]. At present, all FP techniques are quite recent with no hindsight on future fertility for these women.

\section{Surgical ovarian transposition}

Surgical ovarian transposition (SOT) was described in 1958 by McCall et al., and is the oldest FP technique reported [11]. The objective of SOT is to decrease irradiation dose to ovaries by moving them from the pelvic area. Several surgical techniques have been described [12]. The ovary with its pedicle is separated from the uterus and the fallopian tube by sectioning ligaments. The blood supply to the ovaries is provided by the ovarian vessels in the infundibulopelvic ligaments. Dissection of the infundibulopelvic ligaments peritoneum allows mobilization of the ovary which is transposed to the anterolateral abdominal wall, and then sutured to the peritoneum, keeping them outside of the irradiation field. On the inferior border of each ovary, surgical clips are placed to help radiotherapy planning and evaluate received dose. After pelvic irradiation, ovarian transposition preserves endocrine ovarian function in $60-80 \%$ of cases [6]. In a prospective study of 107 women with uterine cervical cancer, Morice $e t$ al. reported a preserved endocrine function in $90 \%$ of cases [13]. Spontaneous pregnancy is possible even without retransposition of the ovaries in the pelvis. In 11 women treated by chemotherapy and pelvic radiotherapy for Hodgkin's lymphoma in childhood and who underwent SOT, Terrenziani et al. reported 14 spontaneous pregnancies with 12 live-births without ovarian retransposition [14]. In a retrospective cohort of six rectal cancer cases, Elizur et al. performed a SOT with OCP for five patients and oocyte vitrification for one. One patient with SOT and OCP obtained a spontaneous pregnancy and live birth, 2 years after the end of oncologic treatments [10]. To our knowledge, there are no other series reporting FP in case of rectal cancer.

Complications of SOT can occur in rare cases, but some are probably under-reported: only two cases of adnexal torsion have been reported [15]. In cancer which is likely to extend to ovarian tissue, special attention must be required to avoid transposition of ovaries with risk of metastasis. Ovarian metastasis are rare and concern less than $1 \%$ of patients with rectal cancer [16]. The risk of ovarian metastasis cannot be totally eliminated but is very low in a localized rectal cancer with macroscopic normal ovaries. A systematic review and meta-analysis of 828 patients with gynecological cancers reported no metastatic ovarian malignancy following SOT [17]. The most frequent complication was the development of benign ovarian cysts which occured in about $15 \%$ of cases. In 2018, ASCO guidelines confirmed that SOT could be used as FP technique for women treated with pelvic radiotherapy [5]. Selter et al. reported that in 828 young women treated by radiotherapy for pelvic malignancy in the USA between 2009 and 2014 , less than $7 \%$ of them undergone a SOT [18]. Our case shows that SOT allowed to preserve endocrine ovarian function and ovarian reserve despite high dose pelvic radiotherapy.

\section{Ovarian cortex cryopreservation}

OCP consists in performing a total or partial ovariectomy to cryopreserve nongrowing follicles of the ovarian reserve into ovarian cortex. This technique aims to reimplant ovarian tissue after remission to restore both endocrine and exocrine ovarian function. OCP is indicated principally in high risk of POF treatments. The delay to program laparoscopy for OCP is relatively short, and it can also be performed in women who require immediate chemotherapy. After reimplantation of ovarian tissue, the endocrine function is restored in $95 \%$ of cases [19]. Meirow et al. have reported the autograft of cryopreserved ovarian tissue from 20 women of which 15 received high-doses 
gonadotoxic chemotherapies before stem cell transplantation [20]. Among them, 19 women presented amenorrhea with menopausal hormonal serums levels after stem cell transplantation. After autograft, 17 women recovered regular periods with a FSH serum level $<16 \mathrm{UI} / 1$. Since the first live-birth after ovarian autograft in 2004, more than 130 live-births have been reported worldwide [19,21]. Live-birth rate after ovarian autograft is among 30\% [22]. However, these results mainly concern hematological malignancies, and few patients have undergone reimplantation of cryopreserved ovarian tissue after pelvic radiotherapy. The study of Diaz-Gracia et al. compared outcome in 49 women who reutilized their vitrified oocytes versus 44 women who cryopreserved ovarian tissue followed by an autograft [22]. The live-birth rate was not significantly different between the two groups but after ovarian autograft, $46.7 \%$ of pregnancies occurred spontaneously. After ovarian autograft, all women except three resumed or improved endocrine ovarian function. Rodriguez-Wallberg et al. reported a case of a in vitro fertilization live-birth after ovarian autograft in a woman wich undergone a 54 Gy pelvic radiotherapy for Ewing's sarcoma [23]. Contrary to oocyte vitrification, reimplantation of cryopreserved ovarian tissue allows obtaining spontaneous pregnancies and endocrine ovarian function recover. A histologic analysis of ovarian medulla and of a cortex biopsy for seeking metastasis is always performed before OCP. Safety of OCP was evaluated by Hoekman et al. who evaluated the ovarian tissue from 47 cancer women who have banked ovarian tissue for FP [24]. Among them, one woman had rectal cancer. Only one woman with an intra-abdominal metastatic esophageal carcinoma had isolated tumoral cells on her cryopreserved ovarian tissue. The risk of ovarian metastasis can't be totally eliminated but is very small in less than $1 \%$ of women with rectal cancer [16]. To date, the rate of reutilization of cryopreserved tissue after cancer remission is low, between 3 and 5\% [22,25], and to this day, this technique still needs evaluation, in particular concerning the risk of relapse if residual disease is present in cortex.

\section{Oocyte vitrification}

In the last ASCO guidelines, oocyte vitrification was described as the 'preferred' FP technique [5]. After a controlled multifollicular ovarian stimulation by gonadotrophins, oocyte retrieval is performed in aim to collect a maximum of mature oocytes [26]. Vitrification is a particular technique of ultra-fast freezing in liquid nitrogen at $-196^{\circ} \mathrm{C}$, permitting cryopreservation of mature oocytes without intracellular crystallization. After thawing, oocytes could be used for in vitro fertilization to get embryos. Ovarian stimulation is possible on a cycle day-independent schedule but still requires in about 12 days to achieve stimulation and oocyte retrieval. There is no data available about the outcome after oocyte vitrification for rectal cancer. Oocyte vitrification major drawback for FP is to leave the ovaries exposed to pelvic radiotherapy with a risk of final POF. Moreover, this technique requires delaying treatment, and often allows achieving a single or two cycles of ovarian stimulation with a limited number of harvested mature oocytes. Oocyte cryopreservation alone does not seem sufficient to preserve fertility and ovarian function in rectal cancer. Each oocyte give among $6 \%$ of chance to obtain a live-birth [27]. In case of POF induced by radiotherapy, the vitrified oocytes will give only the chance to achieve a pregnancy and if the frozen-thawed oocytes are not fertilized and/or if the obtained embryos do not implant, the woman will not have no more chance of pregnancy and no possibility to restore endocrine function by ovarian autograft. If the woman does not recover endocrine ovarian function because her ovaries haven't be transposed or cryopreserved, hormone replacement therapy will also be required.

\section{Strategy in rectal cancer}

In in our opinion, rectal cancer in age-reproductive women requires a specific management. A cohort study would be interesting to assay the number of age-reproductive women referred to oncofertility center for rectum cancer. In our practice, the referred women rate with rectal cancer seems low, about one or two per year and the larger retrospective cohort reported only six women with rectal cancer [6].

For most cancers, oocyte cryopreservation is to date described as the preferred option for FP in ASCO's Guidelines. For a long time, ovarian cryopreservation was considered as an experimental technique, and recommandations have to follow 'emerging data that may prompt reconsideration of this designation in the future'. Recent studies have reported similar live-birth rates after ovarian autograft versus embryo transfer after in vitro fertilization with frozen-thawed oocytes [22].

All the FP techniques (SOT, OCP and oocyte cryopreservation) could be associated together, but technical and time constraints can limit their combination in routine. Indications, benefits and drawbacks of each technique for rectal cancer FP are summarized in Table 2. SOT and OCP aim to protect ovarian tissue from ionizing radiations. For GRECOT's experts, and in our own experience, SOT is technically difficult to perform with ovaries enlarged 


\begin{tabular}{|c|c|c|c|}
\hline Technique & Benefits & Inconvenients & Outcome data \\
\hline $\begin{array}{l}\text { Ovarian cortex } \\
\text { cryopreservation (OCP) }\end{array}$ & $\begin{array}{l}\text { Short delay before starting anticancerous } \\
\text { treatment } \\
\text { Left ovary is less protected from ionizing } \\
\text { radiations, even after SOT, justifying left } \\
\text { ovariectomy for OCP } \\
\text { Full protection of cryopreserved cortex } \\
\text { from irradiation } \\
\text { OCP could be associated with SOT during } \\
\text { the same surgical time } \\
\text { Ovarian autograft permits to restore } \\
\text { endocrine function, sometimes during few } \\
\text { yearsPossibility of spontaneous pregnancy } \\
\text { after ovarian tissue autograft }\end{array}$ & $\begin{array}{l}\text { Requires an additional laparoscopy before } \\
\text { treatment } \\
\text { Requires a second additional laparoscopy } \\
\text { after remission for ovarian autograftThe } \\
\text { quality of the neovascularization of } \\
\text { autografted cortex slices in irradiated } \\
\text { pelvis needs to be evaluated }\end{array}$ & $\begin{array}{l}\text { More than } 130 \text { live births reported after } \\
\text { transplantation of cryopreserved ovarian } \\
\text { cortex } \\
\text { A case of live birth after pelvic irradiation } \\
\text { and transplantation of cryopreserved } \\
\text { ovarian tissue [22] }>90 \% \text { preservation of } \\
\text { ovarian endocrine function } \\
30 \% \text { live birth rate after ovarian } \\
\text { transplantation }\end{array}$ \\
\hline $\begin{array}{l}\text { Ovarian surgical } \\
\text { transposition (SOT) }\end{array}$ & $\begin{array}{l}\text { Short delay before starting anticancerous } \\
\text { treatmentPreserve ovarian endocrine } \\
\text { function }\end{array}$ & $\begin{array}{l}\text { Requires of a supplementary laparoscopy } \\
\text { before starting } \\
\text { anticancerous treatmentOvaries, in } \\
\text { particular the left, are not totally protected } \\
\text { from irradiation } \\
\text { Abdominal pains, functional cysts on } \\
\text { transposed ovaries (15\%) }\end{array}$ & $\begin{array}{l}\text { More than } 80 \% \text { preservation of ovarian } \\
\text { endocrine function } \\
\text { Spontaneous pregnancies are possible } \\
\text { despite transposed ovaries }\end{array}$ \\
\hline Oocyte vitrification & $\begin{array}{l}\text { No additional laparoscopy« preferred " } \\
\text { technique of FP in numerous disease }\end{array}$ & $\begin{array}{l}\text { Requires a delay for ovarian stimulation ( } \\
12 \text { days) before starting anticancerous } \\
\text { treatment } \\
\text { No preservation of endocrine function } \\
\text { Difficulty to associate with other FP } \\
\text { techniques } \\
\text { In vitro fertilization required to achieve } \\
\text { pregnancy } \\
\text { In case of irreversible effects of oncologic } \\
\text { treatments, no other chance of pregnancy } \\
\text { after having used all the vitrified oocyte } \\
\text { stock }\end{array}$ & $\begin{array}{l}>30 \% \text { live birth rate after oocyte thawing } \\
\text { and IVF in cancer patients } \\
\text { No data in rectal cancer, and concerning } \\
\text { implantation rate of embryos in an } \\
\text { irradiated uterus }\end{array}$ \\
\hline
\end{tabular}

FP: Fertility preservation; OCP: Ovarian cortex cryopreservation; SOT: Ovarian surgical transposition.

by ovarian stimulation and oocyte pick-up. Likewise, embryologists reported the difficulties to cut thin slices of ovarian cortex for OCP in a hyperstimulated and hemorrhagic ovary.

In our opinion, although there is no sufficient data on the best FP strategy in rectal cancer, and despite ASCO's guidelines [5], oocyte vitrification alone does not seem to be the most appropriate FP technique because ovarian endocrine function is not protected against ionizing radiations with no chance to restore it after remission. Thus, possible strategies of FP in case of rectal cancer that could be discussed are:

- Bilateral SOT. In a second time, a controlled ovarian stimulation for transcutaneous abdominal ovarian pick-up could be discussed for cryopreserve oocytes. However, in this strategy, oocyte retrieval is technically most difficult.

- Combination of left ovarian OCP and right ovarian SOT

- unilateral ovariectomy (or ovarian bilateral cortex biopsies) for OCP followed by controlled ovarian stimulation for oocyte vitrification [28]

- Ovarian bilateral cortex biopsies for OCP followed in the same surgical time by a bilateral SOT

We aimed to describe different FP techniques that could be proposed. As shown in Table 1, none of the experts gave the same opinion. Finally, we proposed strategies that could be efficient and safe, but that require for each of them further evaluation. More data with a large cohort study are required to evaluate the best strategy for preserving endocrine function and long-term fertility in the specific case of rectal cancer in age-reproductive women. In our case, the patient recovered spontaneous menses with a stable AMH level and had spontaneous pregnancy in few months, confirming efficiency of SOT to preserve ovarian function and fertility. Moreover, this case was the starting point of a national 'brainstorming' between oncofertility French experts that underlined the lack of consensus and the impossibility to recommend a technique instead another for rectal cancer. 


\section{Preservation of uterine function}

Uterus damage due to pelvic radiotherapy should also be considered. The endometrium is a fast renewal tissue, more sensitive to radiation whereas smooth muscle cells of myometrium are a slow renewal tissue with delayed radiation effects. Histological study of irradiated uterus showed atrophic myometrium, with fibrosis and oedema at the serosal surface. The irradiated endometrium is atrophic, with thickened and smaller blood vessels [29]. Radiation exposure may induce reduced uterine volume and decrease the elasticity of uterine muscle that may result in obstetrical complications. Lack of ovarian preservation leads to POF with histological uterine changes because of hormonal deficiency [4]. Two studies evaluated by MRI the effects of pelvic irradiation on the uterus. Milgrom et al. evaluated the uterus by dynamic contrast-enhanced MRI in ten patients with rectal cancer before and after radiotherapy [30]. On T2 MRI, the junctional zone was visible in nine patients before and only in one after RT $(\mathrm{p}=0.001)$. Median cervical length $(2.3$ vs $3.0 \mathrm{~cm})$ and endometrial thickness $(2.6$ vs $5.9 \mathrm{~mm})$ were reduced after RT. Uterine volume, myometrial thickness, myometrial and cervical signal intensity were not significantly different between pre- and post-RT examinations. For decreasing uterine irradiation, various techniques of uterine transposition have been described in patients with rectal cancer, but they are still experimental and require further evaluation [31]. Pelvic radiotherapy is associated with an increased risk of maternal and neonatal complications. Haggar $e$ al. studied maternal and neonatal outcomes in 232 women treated for colorectal cancer. Compared with colon cancer, rectal cancer was independently associated with a significantly higher risk of overall maternal and neonatal adverse outcomes (odds ratios: 3.73 and 2.73, respectively), as well as after radiotherapy (odds ratios: 4.24 and 2.81, respectively) [32]. Radiotherapy in prone position has been proposed by radiation oncologists to decrease radiations to small bowel and bladder in rectal cancer [33]. In our case, because of a retroverted uterus, the radiation oncologist counseled to perform radiotherapy in prone position to decrease uterine irradiation dose without undertreating rectal cancer. To our knowledge, no data are available about the efficiency of prone position radiotherapy to decrease uterine damage and preserve fertility in rectal cancer. In the case we reported, 2 years after treatment, the abundance of the menses associated at a normal thickness of the peri-implantation endometrium give us hope that prone position for radiotherapy could have protected her uterus. Moreover, post-treatment MRI did not show anatomical macroscopic differences after radiotherapy. However, despite these reassuring data, this woman has an early miscarriage.

\section{Conclusion}

Rectal cancer in young-age-reproductive women is a rare condition with a high risk of impaired fertility. However, in France, the question of FP for rectal cancer concerns about 200 young women per year and should be considered. Several strategies combining different FP techniques as SOT, OCP and/or oocyte vitrification can be discussed. In rectal cancer, FP must have two main objectives: preserving uterus and ovarian endocrine function from ioninizing radiations and preserving gametes for restoring fertility. Despite limited data, SOT associated or not with OCP are both techniques that seem most suitable to preserve both fertility and endocrine function in rectal cancer. However, cohort studies are required to evaluate the best strategy for preserving endocrine function and long-term fertility. Our first instinct that was asking our colleagues from all the country for seeking ultra-specialized advices leads us to set-up in 2016 - with the technical help of the French Regional Cancer network and thank to a health public financial support - an national e-meeting cancer $\&$ fertility to share medical opinions and experiences in case of rare cancers [34].

\section{Future perspective}

The FP has become a major issue in the cancer management of reproductive-age women. For a lot of cancers in young women, there is a lack of data and consensus for deciding 'best' FP strategy. When facing with a rare and/or complex case, oncofertility practitioners need to share experiences and advices with 'ultra specialized' colleagues for helping them to decide the best FP strategy. We believe that the set-up of a 'e-network' composed by national oncofertility experts, and why not in the future by international experts, could improve the oncofertility patient's care. Our first French national e-meeting for oncofertility complex situations is maybe the first step before a large collaborative oncofertility care e-network (http://www.oncopaca.org/fr/page/e-meeting-interregional-cas-complex es-cancer-et-fertilite). 


\section{Executive summary}

\section{Surgical ovarian transposition}

- Surgical ovarian transposition (SOT) is a surgical technique of fertility preservation that aim to decrease irradiation dose to ovaries by moving them from the pelvic area and that allow to preserve endocrine ovarian function in $60-80 \%$ of cases.

- Spontaneous pregnancy is possible even without retransposition of the ovaries in the pelvis.

Ovarian cortex cryopreservation

- Ovarian cortex cryoconservation (OCP) aims to cryopreserve nongrowing follicles of the ovarian reserve into ovarian cortex for grafting ovarian tissue after remission to restore both endocrine and exocrine ovarian function.

- OCP is indicated principally before high risk of premature ovarian failure treatments.

- More than 130 pregnancies have been reported after autograft of frozen-thawed ovarian cortex.

Oocyte vitrification

- Oocyte retrieval is performed after ovarian controlled stimulation in aim to collect a maximum of mature oocytes before vitrification.

- This technique needs a delay for ovarian stimulation ( $~ 12$ days) before starting anticancerous treatment.

- Despite good live-birth rate after thawing and in vitro fertilization, oocyte vitrification does not preserve ovarian endocrine function.

Strategies that could be discussed in rectal cancer

- Oocyte vitrification alone does not seem to be the most appropriate FP technique in rectal cancer.

- Bilateral surgical ovarian transposition (SOT). In a second time, a controlled ovarian stimulation for transcutaneous abdominal ovarian pick-up could be discussed for cryopreserving oocytes. However, in this case, oocyte retrieval is technically most difficult.

- Combination of left ovarian OCP and right ovarian SOT.

- Unilateral ovariectomy or ovarian bilateral biopsies for OCP first, followed by COS with transvaginal ovarian pick-up for oocyte cryopreservation.

- Ovarian bilateral biopsies for OCP followed in the same surgical time by a bilateral SOT.

- Cohort studies are required to evaluate long-term outcome after FP for rectal cancer and to determine the best strategy for preserving both endocrine function and long-term fertility in rectal cancer.

Preservation of uterine function

- High dose pelvic radiotherapy leads to endometrium and myometrium damage.

- Pelvic radiotherapy is associated with an increased risk of maternal and neonatal complications.

- Prone position for radiotherapy should be discussed for decreasing the total dose of irradiation received on the uterus.

- Various surgical techniques of uterine transposition have been described in patients with rectal cancer but are still experimental.

\section{Acknowledgments}

Authors thank A Zaccariotto, MD, for her precious technical help. We also thank all the French experts in oncofertility for their contributions to the collegial reflexion on this case, and for sharing their clinical experience to enhance the fertility preservation's care through the national e-meeting Cancer and Fertilité.

\section{Financial \& competing interests disclosure}

The authors have no relevant affiliations or financial involvement with any organization or entity with a financial interest in or financial conflict with the subject matter or materials discussed in the manuscript. This includes employment, consultancies, honoraria, stock ownership or options, expert testimony, grants or patents received or pending, or royalties.

No writing assistance was utilized in the production of this manuscript.

\section{References}

Papers of special note have been highlighted as: $\bullet$ of interest; $\bullet \bullet$ of considerable interest

1. Bailey CE, Hu C-Y, You YN et al. Increasing disparities in the age-related incidences of colon and rectal cancers in the United States, 1975-2010. JAMA Surg. 150(1), 17-22 (2015).

2. Glynne-Jones R, Wyrwicz L, Tiret E et al. Rectal cancer: ESMO Clinical Practice Guidelines for diagnosis, treatment and follow-up. Ann. Oncol. 28(suppl.4), iv22-iv40 (2017).

3. Mazeron R, Maroun P, Cao K et al. Impact of radiotherapy on female fertility. Bull. Cancer 102(5), 470-476 (2015). 
4. Teh WT, Stern C, Chander S, Hickey M. The impact of uterine radiation on subsequent fertility and pregnancy outcomes. BioMed Res. Int. 2014, Article ID 482968, 8 (2014).

5. Oktay K, Harvey BE, Partridge AH et al. Fertility preservation in patients with cancer: ASCO Clinical Practice Guideline update. J. Clin. Oncol. 36(19), 1994-2001 (2018).

- American Society of Clinical Oncology (ASCO) Guidelines to manage fertility preservation (FP) in patient with cancer.

6. Irtan S, Orbach D, Helfre S, Sarnacki S. Ovarian transposition in prepubescent and adolescent girls with cancer. Lancet Oncol. 14(13), e601-e608 (2013).

- A comprehensive review about indications, techniques and results of surgical ovarian transposition for FP in young patients.

7. Ben-Aharon I, Shalgi R. What lies behind chemotherapy-induced ovarian toxicity? Reproduction 144(2), 153-163 (2012).

8. Levi M, Hasky N, Stemmer SM, Shalgi R, Ben-Aharon I. Anti-Müllerian hormone is a marker for chemotherapy-induced testicular toxicity. Endocrinology 156(10), 3818-3827 (2015).

9. ten Broek RPG, Issa Y, van Santbrink EJP et al. Burden of adhesions in abdominal and pelvic surgery: systematic review and met-analysis. BMJ 347, f5588 (2013).

10. Elizur SE, Tulandi T, Meterissian S, Huang JYJ, Levin D, Tan SL. Fertility preservation for young women with rectal cancer-a combined approach from one referral center. J. Gastrointest. 13(6), 1111-1115 (2009).

-. To date, the only retrospective cohort of six fertility preservation for rectal cancer. All patients had surgical ovarian transposition and five associated ovarian cortex cryoconservation. One of them had spontaneous pregnancy and a live birth.

11. McCall ML, Keaty EC, Thompson JD. Conservation of ovarian tissue in the treatment of carcinoma of the cervix with radical surgery. Am. J. Obstet. Gynecol. 75(3), 590-600 (1958).

12. Moawad NS, Santamaria E, Rhoton-Vlasak A, Lightsey JL. Laparoscopic ovarian transposition before pelvic cancer treatment: ovarian function and fertility preservation. J. Minim. Invasive Gynecol. 24(1), 28-35 (2017).

13. Morice P, Juncker L, Rey A, El-Hassan J, Haie-Meder C, Castaigne D. Ovarian transposition for patients with cervical carcinoma treated by radiosurgical combination. Fertil. Steril. 74(4), 743-748 (2000).

14. Terenziani M, Piva L, Meazza C, Gandola L, Cefalo G, Merola M. Oophoropexy: a relevant role in preservation of ovarian function after pelvic irradiation. Fertil. Steril. 91(3), 935.e15-935.e16 (2009).

15. Gómez-Hidalgo NR, Darin MC, Dalton $\mathrm{H}$ et al. Ovarian torsion after laparoscopicovarian transposition in patients with gynecologic cancer: a report of two cases. J. Minim. Invasive Gynecol. 22(4), 687-690 (2015).

16. Riihimäki M et al. Patterns of metastasis in colon and rectal cancer. Sci. Rep. 6, 29765; doi: 10.1038/srep29765 (2016) (Epub ahead of print).

17. Gubbala K, Laios A, Gallos I, Pathiraja P, Haldar K, Ind T. Outcomes of ovarian transposition in gynaecological cancers; a systematic review and meta-analysis. J. Ovarian Res. 7, 69 (2014).

18. Selter J, Grossman Becht LC, Huang Y et al. Utilization of ovarian transposition for fertility preservation among young women with pelvic malignancies who undergo radiotherapy. Am. J. Obstet. Gynecol. 219(4), 415-417 (2018).

19. Donnez J, Dolmans M-M. Fertility preservation in women. N. Engl. J. Med. 377(17), 1657-1665 (2017).

- OCP allows to have endocrine function restored in $95 \%$ of cases after treatment and return cryopreserved tissue.

20. Meirow D, Ra'anani H, Shapira M et al. Transplantations of frozen-thawed ovarian tissue demonstrate high reproductive performance and the need to revise restrictive criteria. Fertil. Steril. 106(2), 467-474 (2016).

21. Donnez J, Dolmans MM, Demylle D et al. Livebirth after orthotopic transplantation of cryopreserved ovarian tissue. Lancet Lond. Engl. 364(9443), 1405-1410 (2004).

22. Diaz-Garcia C, Domingo J, Garcia-Velasco JA et al. Oocyte vitrification versus ovarian cortex transplantation in fertility preservation for adult women undergoing gonadotoxic treatments: a prospective cohort study. Fertil. Steril. 109(3), 478-485.e2 (2018).

23. Rodriguez-Wallberg KA, Karlström P-O, Rezapour M et al. Full-term newborn after repeated ovarian tissue transplants in a patient treated for Ewing sarcoma by sterilizing pelvic irradiation and chemotherapy. Acta Obstet. Gynecol. Scand. 94(3), 324-328 (2015).

24. Hoekman EJ, Smit VTHBM, Fleming TP, Louwe LA, Fleuren GJ, Hilders CGJM. Searching for metastases in ovarian tissue before autotransplantation: a tailor-made approach. Fertil. Steril. 103(2), 469-477 (2015).

25. Jadoul P, Guilmain A, Squifflet J et al. Efficacy of ovarian tissue cryopreservation for fertility preservation: lessons learned from 545 cases. Hum. Reprod. Oxf. Engl. 32(5), 1046-1054 (2017).

26. Argyle CE, Harper JC, Davies MC. Oocyte cryopreservation: where are we now? Hum. Reprod. Update 22(4), 440-449 (2016).

27. Doyle JO, Richter KS, Lim J, Stillman RJ, Graham JR, Tucker MJ. Successful elective and medically indicated oocyte vitrification and warming for autologous in vitro fertilization, with predicted birth probabilities for fertility preservation according to number of cryopreserved oocytes and age at retrieval. Fertil. Steril. 105(2), 459-466.e2 (2016).

28. Dolmans M-M, Marotta M-L, Pirard C, Donnez J, Donnez O. Ovarian tissue cryopreservation followed by controlled ovarian stimulation and pick-up of mature oocytes does not impair the number or quality of retrieved oocytes. J. Ovarian Res. 7, 80 (2014). 
29. Letur-Könirsch H, Lefaix J-L, Delanian S. Uterus after irradiation. Gynecol. Obstet. Fertil. 33(9), 605-609 (2005).

30. Milgrom SA, Vargas HA, Sala E, Kelvin JF, Hricak H, Goodman KA. Acute effects of pelvic irradiation on the adult uterus revealed by dynamic contrast-enhanced MRI. Br. J. Radiol. 86(1031), 20130334 (2013).

31. Ribeiro R, Rebolho JC, Tsumanuma FK, Brandalize GG, Trippia CH, Saab KA. Uterine transposition: technique and a case report. Fertil. Steril. 108(2), 320.e1-324.e1 (2017).

32. Haggar F, Pereira G, Preen D et al. Maternal and neonatal outcomes in pregnancies following colorectal cancer. Surg. Endosc. 27(7), 2327-2336 (2013).

- Maternal and neonatal outcomes in 232 women treated for colorectal cancer; rectal cancer was independently associated with a significantly higher risk of overall maternal and neonatal adverse outcomes versus colon cancer.

33. Koeck J, Kromer K, Lohr F et al. Small bowel protection in IMRT for rectal cancer: a dosimetric study on supine vs. prone position. Strablenther. Onkol. Organ Dtsch. Rontgengesellschaft Al. 193(7), 578-588 (2017).

34. Courbiere B, Saias-Magnan J, Bottin P et al. Pilot study of a French fertility preservation e-meeting. Médecine Reprod. 20(1), 32-37 (2018). 
